Proposta de estradas-parque como unidade de conservação: dilemas e diálogos entre o Jalapão e a Chapada dos Veadeiros Veruska Dutra, Aracélio Colares, Lúcio Flavo Marini Adorno, Keile Magalhães, Kelson Gomes

\title{
PROPOSTA DE ESTRADAS-PARQUE COMO UNIDADE DE CONSERVAÇÃO: DILEMAS E DIÁLOGOS ENTRE O JALAPÃO E A CHAPADA DOS VEADEIROS
}

\section{Greenway as a consevation unit proposal: dilemmas and dialogue between Jalapão and Chapada dos Veadeiros}

Veruska Dutra Mestre em Ciências do Ambiente - UFT. Email: veruskadutra@yahoo.com.br

Aracélio Colares Biólogo, Mestre em Ciências do Ambiente - UFT. Email: avcolares@yahoo.com.br

Lúcio Flavo Marini Adorno Prof. Dr. Universidade Federal do Tocantins - UFT. Email: adornolf@gmail.com.br

Keile Magalhães Mestre em Ciências do Ambiente - UFT. Email: keile@uft.edu.br

Kelson Gomes Mestre em Ciências do Ambiente - UFT. Email: kelsondg @ yahoo.com.br

Artigo recebido para publicação em 01/03/2007 e aceito para publicação em 18/03/2008

RESUMO: $\quad$ Este artigo é resultado de um estudo realizado em duas diferentes Unidades de Conservação de forte interesse ecoturístico e conservacionista, por meio de pesquisas bibliográficas e entrevistas abertas sobre Estrada-Parque. Objetivou-se analisar os fundamentos que dão sustentação ao conceito, compreender os desafios colocados e o nível de adequação que revelam a necessidade de legitimidade do uso dessa categoria de unidade de conservação como ferramenta da política ambiental.

Palavras-chave: Estrada-Parque. Conservação. Política Ambiental.

ABSTRACT: This article is a result of a study released in two different Unities of Conservation of strong ecotouristic and conservationistic interest, through bibliographical researches and open interviews, about Greenway. The aim was to analyse the beddings that support this concept, to understand the involved challenges and the level of adequacy that discloses the necessity of legitimacy of the use of this unit category of conservation as a tool for the environmental politics.

Keywords: Greenway. Conservation. Environmental Politics.

Sociedade \& Natureza, Uberlândia, 20 (1): 161-176, jun. 2008 
Proposta de estradas-parque como unidade de conservação: dilemas e diálogos entre o Jalapão e a Chapada dos Veadeiros Veruska Dutra, Aracélio Colares, Lúcio Flavo Marini Adorno, Keile Magalhães, Kelson Gomes

\section{INTRODUÇÃO}

O modelo de desenvolvimento implantado pelo Governo Federal durante as décadas de 1960 a 1980 incluía a construção de grandes rodovias que visavam cumprir as metas de desenvolvimento e melhorar a infra-estrutura de transporte rodoviário.

De acordo com Araújo (2001) as estradas são tradicionalmente concebidas com duas utilidades, tendo significância tanto econômica quanto social como corredores de transporte e utilidades. Elas também podem ter significativos impactos sobre o meio ambiente, por atravessarem habitats de vida selvagem e por serem também um dos mais destruidores elementos dos processos de fragmentação destes habitats.

A inclusão da questão ambiental nas discussões políticas atuais ainda é considerada como algo recente, iniciada a partir de 1970 , com a realização da conferência de Estocolmo, na Suécia. Desde então, o debate ambiental tornou-se essencial e passou a ser reivindicado pelos mais diversos setores representativos da sociedade, como por exemplo: sindicatos, associações e Organizações NãoGovernamentais (ONGs). Isso fez com que essa discussão ambiental começasse a integrar a plataforma política dos gestores públicos.

Diferentemente das consideradas políticas tradicionais, como as de transporte, agricultura e indústria que, quando implementadas poderão transformar-se, em um determinado período de tempo, em benefícios facilmente identificáveis para a população, a política ambiental possui caráter sui generis, pois além de ser dirigida a toda sociedade, incluindo as gerações futuras, ela enfatiza o que não deveria ser feito na implantação de políticas teoricamente positivas. Entretanto, essa característica deve-se, principalmente, a uma falta de compreensão do seu lado positivo, que é o lado em que ela permite, e ao mesmo tempo demonstra, a diversidade de recursos disponíveis, fornecendo assim uma base sustentável para a manutenção da sociedade (MOURA, 1996, p. 53).
A política ambiental surge, então, como uma mediadora na aplicação e continuidade da política agrária e econômica. Os gestores públicos a utilizam como um dispositivo facilitador na implementação dessas políticas, como as estradas-parque.

No cenário brasileiro, é certo que a gestão de estradas, como unidades de conservação - EstradasParque é um tema polêmico, pois há pouca literatura disponível sobre o assunto. Arcari \& Da-Ré (apud Silva 1998, p. 2), definem esta categoria como:

um parque linear de alto valor educativo, cultural, recreativo e panorâmico que protege faixas de terra ao longo de trechos ou a totalidade de caminhos, estradas ou vias de acesso, e cujos limites são estabelecidos com vistas à proteção de suas características e mantidos em estado natural ou seminatural, evitando-se obras que desfigurem o meio ambiente.

A avaliação de Estradas-Parque (EP), como uma categoria que tenha ou não efetividade de manejo, vem sendo discutida desde a década de 1970 no Brasil, ainda da ocasião do primeiro plano de Sistema de Unidades de Conservação do Brasil (SNUC) (DOUROJEANNI 2003,16).

O estabelecimento de unidades de conservação, no país, está em sua terceira concepção, ou seja, o chamado SNUC, mas seja pela decorrência das antigas legislações - Código Florestal (1934/ 1965) e do aparelho público - IBDF (Instituto Brasileiro do Desenvolvimento Florestal), desde 1979 a categoria Estrada-Parque estava prevista como uma unidade de conservação, muito embora em âmbito federal não tenha sido criada nenhuma no país. Por encomenda do IBDF, a FUNATURA (Fundação PróNatureza), em 1988, foi incumbida de apresentar um novo anteprojeto de sistema nacional de unidades de conservação, coordenada por sua presidente, Maria Tereza Jorge de Pádua, que mantinha nessa versão a continuidade de EPs como uma categoria de unidade de conservação. Após vários workshops, no ano seguinte, esse documento foi entregue ao recém criado Instituto Brasileiro do Meio Ambiente e dos Recursos Naturais Renováveis (IBAMA), ficando sem

Sociedade \& Natureza, Uberlândia, 20 (1): 161-176, jun. 2008 
regulamentação, até que em 1992 foi enviado à Câmara dos Deputados, recebendo um substitutivo preliminar sob a relatoria do Deputado Fábio Feldmann, em 1994. Nesse substitutivo eram mantidas as EPs, passando por mais seis anos de discussões e processo de negociações, naquela casa legislativa, até a definição de seu formato final em 19 de julho de 2000.

Quando dessas novas discussões na segunda metade dos anos noventa sobre a elaboração dessa uniformização do sistema nacional, houve uma forte divisão entre os chamados preservacionistas e os socioambientalistas, questionando a validade e efetividade de algumas categorias, entre elas as EPs, ora pelas análises quanto aos princípios biogeográficos de proteção como a Teoria do Equilíbrio de Biogeografia Insular (TEBI), segundo abordagem de MacArthur \& Wilson (1963), ora pela falta de inclusão de comunidades tradicionais nas unidades na implementação de qualquer categoria de conservação, o que, conseqüentemente, causava sérios transtornos ou mesmo conflitos em detrimento da implementação dos planos de manejo.

Como parte desse longo debate, ganhou forma a criação de Áreas de Proteção Ambiental (APAs), como a alternativa considerada mais viável como unidade de conservação de uso sustentável, excluindo, assim, categorias tanto da primeira como da segunda versão do Plano de Sistema de Unidades de Conservação: Estradas-Parque, área de interesse turístico, reserva florestal, entre outras.

Mesmo com a criação do SNUC em 2000, as EPs não foram consideradas como uma categoria de unidade de conservação, mas, no entanto, ela vem sendo utilizada com freqüência pelos órgãos públicos ambientais municipais e estaduais, como nos Estados do Acre e do Tocantins, ao instituírem o seu Sistema Estadual de Unidades de Conservação (SEUC) da Natureza, incluindo a Estrada-Parque como um dos componentes da Unidade de Uso Sustentável, bem como no Estado do Mato Grosso do Sul que em seu decreto $\mathrm{n}^{\circ} 9.937 / 2000$, Art $1^{\circ}$, cria a área de proteção ambiental denominada Estrada-Parque de Piraputanga.

A criação de uma Estrada-Parque pode gerar conflitos porque são implantadas em estradas já existentes e utilizadas pela população local sem restrições de uso. Com a formação da unidade de conservação são estabelecidas normas de legislação ambiental limitando o seu uso direto.

A Estrada-Parque, em sua maioria, é implantada em áreas de interesse turístico e conservacionista, o que pode acarretar em aumento significativo de fluxos turísticos e trazer impactos negativos à comunidade, como à inserção de culturas externas, o aumento da criminalidade e a especulação imobiliária. Paradoxalmente, se esse fluxo já existir de qualquer maneira, ela pode se transformar numa ferramenta de ordenamento territorial e gestão ambiental compartilhada.

Considerando-se a deficiência dos estudos sobre as Estradas-Parques, percebeu-se a necessidade da realização de uma pesquisa in loco sobre esse tema, por meio de um estudo de caso sobre uma proposta de implantação de Estradas-Parques na região do Jalapão, entre os municípios de São Felix e Mateiros, no Estado do Tocantins e a Estrada-Parque recentemente implantada na Chapada dos Veadeiros (segundo divulgação oficial do governo do Estado de Goiás), no município de Alto Paraíso, entre a sua sede e o povoado de São Jorge, Estado de Goiás. Esses dois pólos são de forte interesse ecoturístico - conservacionista.

O estudo visou identificar, de maneira crítica os fundamentos que dão sustentação aos projetos de criação de Estradas-Parque, nestas regiões. Utilizando o método indutivo, formaram-se argumentos sobre a temática em questão por meio de pesquisas bibliográficas e entrevistas abertas com as comunidades locais ${ }^{1}$ e seus gestores. Optou-se, inicialmente, por esse método de investigação com a

\footnotetext{
${ }^{1}$ Essas entrevistas ocorreram entre os meses de Outubro e Novembro de 2005, nos dois trechos viários, identificando a visão do lugar de seus moradores e transeuntes, bem como sua compreensão e avaliação sobre os trechos enquanto uma Estrada-Parque. Nas citações do trabalho criou-se nome fictício às pessoas entrevistadas, por terem sido realizadas de cunho informal.
} 
finalidade de considerar a percepção ambiental local como um forte fator elucidativo de interpretação do tema em estudo enraizado pelos olhares da cultura local. Assim, o direcionamento da investigação procurou identificar localmente como foi e está sendo o processo de incorporação dessa matriz discursiva modelante, ou seja, a interação de um modelo exógeno chamado "Estrada-Parque" à compreensão (literalmente implicando na forma local de experimentá-la como o conceito-chave aplicável pelos agentes locais) da cultura local.

\section{Jalapão}

O Jalapão está localizado na região leste do Estado do Tocantins, tendo como portal de entrada Ponte Alta do Tocantins, distante aproximadamente 200 km da cidade de Palmas, capital do Estado. A região do Jalapão abrange os municípios: Ponte Alta do Tocantins, Mateiros, São Felix do Tocantins, Rio do Sono, Lizarda, Lagoa do Tocantins, Santa Tereza do Tocantins e Novo Acordo. Figura 1.

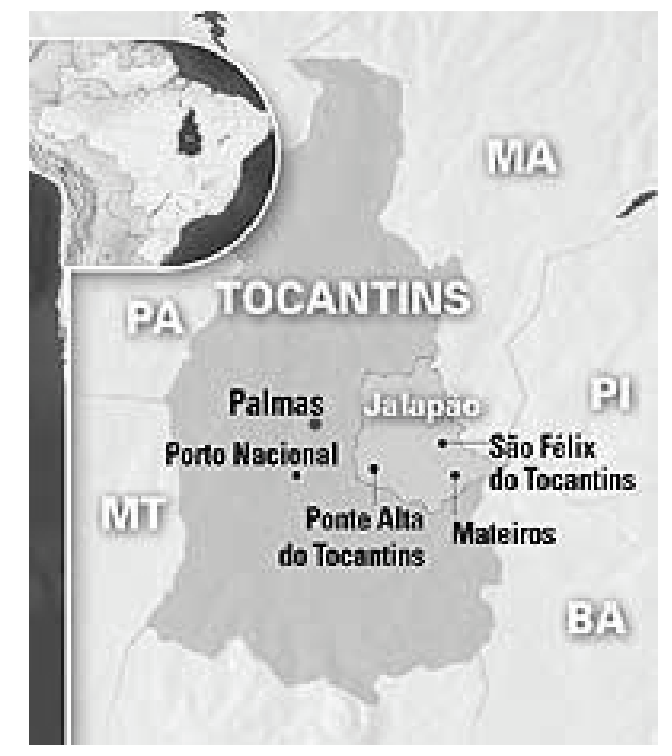

Figura 1. Mapa ilustrativo de localização da Região do Jalapão - TO

Fonte: www.bsb.netium.com.br/ivan/jalapao/jalapao.jpg:

É uma região recortada por serras, nascentes de riachos cristalinos, caracterizada por um clima seco e quente com dois períodos distintos: chuvas (de outubro a abril) e seca (de maio a setembro). Possui vegetação diversificada, com cerrados, campos, e plantas de grande importância madeireira, ornamental e medicinal. É composta por três biomas: caatinga, cerrado e clima da Amazônia (BEHR, 2002).

Segundo Diagnóstico realizado pela Secretaria de Planejamento do Meio Ambiente do Tocantins (SEPLAN) (1996) o Jalapão é uma região isolada e pouco desenvolvida. O modo de vida das comunidades locais é representado pela agricultura de subsistência, por meio de pequenos proprietários rurais que ainda exploram o solo por meio de queimadas e desmatamentos, comprometendo algumas áreas. Como meio de subsistência, praticam atividades como o artesanato de capim dourado (uma planta nativa da região com coloração dourada), confeccionando bolsas, tapetes, chapéus, cestas. Esse artesanato constituindo-se numa das principais fontes de renda dessas comunidades.

\footnotetext{
2 Parque Estadual do Jalapão, Área de Proteção Ambiental do Jalapão, Estação Ecológica da Serra Geral e Parque Nacional das nascentes do Parnaíba.
} 
Por meio da lei federal, $\mathrm{n}^{\circ} 9.985$ de 18 de julho de 2000, foram formadas quatro unidades de conservação ${ }^{2}$ e corredores ecológicos no Jalapão, com o intuito de preservar o ecossistema, que é frágil e raro, propiciando o desenvolvimento de pesquisas científicas e propostas para um aproveitamento sustentável.

Embora seja uma região isolada, vem despertando o interesse de muitos turistas. O lugar é repleto de paisagens cênicas e atrativos como: dunas, fervedouros, cachoeiras e rios que possibilitam a prática do ecoturismo. Figura 2.

Nesta região, há uma proposta de implantação de uma Estrada-Parque ligando São Felix do Tocantins a Mateiros, com extensão de $60 \mathrm{~km}$. Essa proposta foi registrada no diagnóstico turístico da região, realizado pela SEPLAN em 2001 por meio da Ruschmann Consultores ${ }^{3}$.

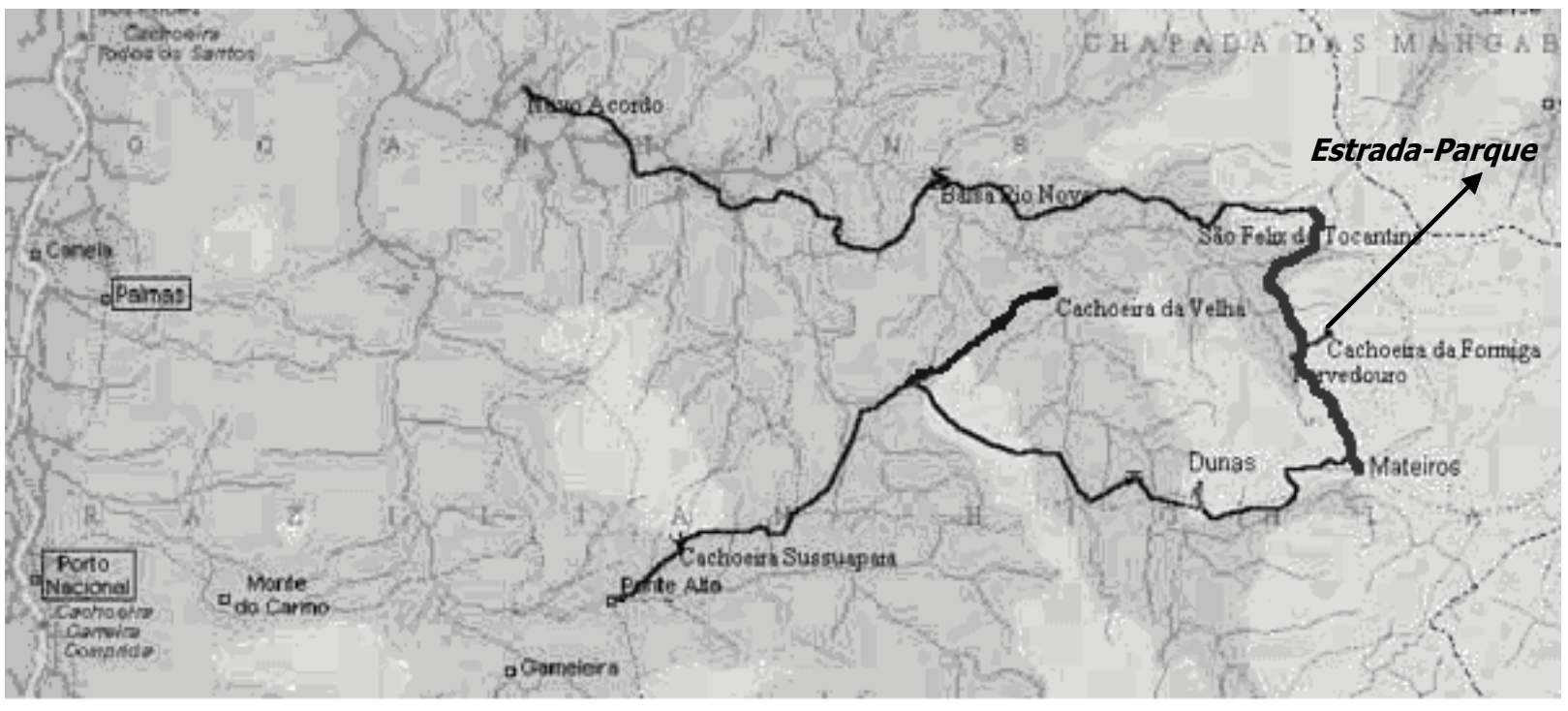

Figura 2. Mapa modificado para ilustrar a localização da proposta de implantação de uma Simulação da Estrada-Parque Fonte: www.bsb.netium.com.br/ivan/jalapao/jalapao.jpg:

A proposta de Estrada-Parque no Jalapão, entre São Felix do Tocantins e Mateiros, objetiva preservar os recursos e atrativos a serem visitados nesta região. Esta rodovia circunda o Parque Estadual do Jalapão (PEJ) e em alguns trechos atravessa parte deste parque.

Criado pela lei $\mathrm{n}^{\circ} 1.224$ de 11 de maio de 2001, o Parque Estadual do Jalapão com aproximadamente 150.000 hectares. O objetivo da sua criação é a proteção do seu ecossistema frágil, caracterizado por rochas arenosas, formadas por depósitos marinhos há bilhões de anos, e fauna representativa que abriga espécies raras e ameaçadas de extinção.
É o maior Parque do Estado, cuja posição é estratégica como elo de continuidade entre as áreas protegidas pela APA do Jalapão, Estação Ecológica da Serra Geral e Parque Nacional das nascentes do Parnaíba, formando um mosaico de Unidades de Conservação ${ }^{4}$.

\section{Chapada dos Veadeiros}

A Chapada dos Veadeiros está localizada no Estado de Goiás, no município de Alto Paraíso, a 230 km de Brasília/DF, considerado por muitos como um santuário goiano da ecologia e do misticismo. $\mathrm{O}$

\footnotetext{
3 Empresa de consultoria especializada em turismo.

4 Disponível em: www.seplan.to.gov.br/dma/areas_protegidas/area_protegida_informacoes_uc.htm. Acesso em: 01/12/2005
} 
município é um dos mais apreciados cartões-postais de Goiás.

Encontra-se em São Jorge (distrito de Alto Paraíso), o Parque Nacional da Chapada dos Veadeiros que foi criado pelo Decreto Federal n. ${ }^{\circ}$ 9.875 em 11/01/1961, sua área, inicialmente era de 600 mil hectares, em 2001 houve uma redução da área para 60 mil hectares ${ }^{5}$. Constitui-se em uma importante área de preservação ambiental do Cerrado de altitude, uma vez que é habitada por muitas espécies ameaçadas de extinção como o veadocampeiro, o lobo-guará, a capivara, emas e tucanosde-bico-amarelo. Figura 3.

Já ao longo da estrada, de acesso (GO-239), observa-se o Morro da Baleia no km 18 e as Veredas do Jardim de Maytréia (km20). Por sua vez na GO118 avista-se o ponto mais alto de Goiás (1676 m) no mirante do Pouso Alto.

O principal rio que corta o Parque Nacional é o rio Preto, afluente do rio Tocantins, que comporta belíssimas cachoeiras e antigas formações rochosas, consideradas uma das mais antigas do planeta. $\mathrm{O}$ Parque também preserva áreas de antigos garimpos, como parte da história local e que, segundo o IBAMA, foi declarado Patrimônio Mundial Natural em 2001 pela UNESCO.

Fora do domínio do Parque e ainda no distrito de São Jorge, encontramos o Vale da Lua onde o rio São Miguel corre entre rochas que impressionam pelas cores e pelas formas esculturais talhadas pela força da água através dos tempos. Os artesanatos elaborados com plantas regionais (flores, frutos e sementes), comercializados com o nome "Flores do Cerrado", juntamente com o turismo, garimpo de cristal, a agricultura e a pecuária de subsistência representam a base da economia da região.

Nesta região está sendo implantada uma estrada, denominada "Estrada-Parque Chapada dos Veadeiros", que liga Alto Paraíso de Goiás ao município de Colinas do Sul passando pelo distrito de São Jorge, com 72 km de extensão. Em novembro de 2005, havia sido asfaltados $28 \mathrm{~km}$, restando 13 km para a pavimentação até São Jorge.

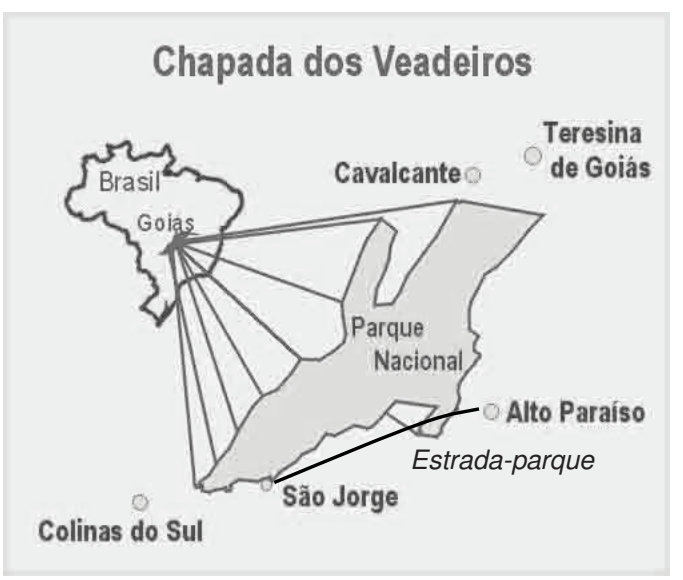

Figura 3. Mapa modificado para ilustrar a Região da Chapada dos Veadeiros - GO, com a Estrada-Parque Fonte: http://www.viaecologica.com.br/guiasecologicos/veadeiros/imagens/mapas/veadeiros.htm:

A proposta dessa estrada foi feita de acordo com o Estudo de Impacto Ambiental - EIA/RIMA da estrada (1998:1-2), devido:
[...] aos aspectos ambientais relevantes da região visando definir um projeto que atendesse aos interesses da população envolvida e que ao mesmo

5 Disponível em: http://www.estadao.com.br/ciencia/noticias/2003/ago/15/271.htm. Acesso em: 27/11/2005.

Sociedade \& Natureza, Uberlândia, 20 (1): 161-176, jun. 2008 
Proposta de estradas-parque como unidade de conservação: dilemas e diálogos entre o Jalapão e a Chapada dos Veadeiros Veruska Dutra, Aracélio Colares, Lúcio Flavo Marini Adorno, Keile Magalhães, Kelson Gomes

tempo fosse compatível com a susceptibilidade geoambiental desse trecho, dessa forma optou-se por um projeto de Estrada-Parque com ciclovia e estruturas turísticas e de apoio adjacentes á pista de rolamento e faixa de domínio. Dessa forma a rodovia terá características de Estrada-Parque oferecendo aos usuários, opções de paradas em pontos de contemplação do interessante cenário local, especialmente no percurso entre Alto Paraíso e o distrito de São Jorge.

\section{UNIDADE DE CONSERVAÇÃO ESTRADA- PARQUE}

Segundo Bernardes (2005), existem, no planeta diversas áreas protegidas, cada uma delas com diferentes objetivos e funções voltadas para a conservação da diversidade biológica, proteção da paisagem, investigação científica, lazer, ecoturismo, dentre outras. A existência destas áreas pode estar associada direta ou indiretamente na origem de muitas outras atividades, sendo a criação de zonas protegidas, para muitos países, um meio eficaz de conservação in situ dos ecossistemas naturais, bem como dos valores culturais das populações que habitam nessas zonas ou nas suas proximidades.

As Unidades de Conservação surgem, portanto, como alternativa para essas áreas ou zonas protegidas. De acordo com o SNUC - Sistema Nacional de Unidades de Conservação (lei federal ${ }^{\circ}$ 9985/2000) - Unidade de Conservação é conhecida como "espaço territorial e seus recursos ambientais, incluindo as águas jurisdicionais, com características naturais relevantes, legalmente instituído pelo Poder Público, com objetivos de conservação definidos, sob regime especial de administração, ao qual se aplicam garantias adequadas de proteção".

O SNUC (2000) classifica as UCs em dois grupos: Unidades Conservação de Proteção Integral, com a finalidade de conservação e pesquisa - são as reservas biológicas, estações ecológicas, parques nacionais e monumentos naturais e Unidades de Conservação de Uso Sustentável. Essas Unidades permitem a exploração sustentável, racional e controlada dos recursos naturais, constituindo-se principalmente, em áreas de proteção ambiental, áreas de relevante interesse ecológico, florestas nacionais, reservas extrativas, reservas de fauna, reservas de desenvolvimento sustentável e reservas particulares do patrimônio natural.

Existem algumas categorias de UCs em outros países que não foram contempladas no Brasil, como as Estradas-Parque. Estas tiveram sua origem nos Estados Unidos tendo como referência os anos de 1913 a 1930. Neste período, foram construídas quatro estradas, com rotas cênicas ou históricas, no Condado de Westchester - Nova York: Rio Bronx (a primeira a ser construída), Rio de Hutchinson, Rio da Serra do Moinho e Condado Transversal. Essas estradas foram criadas com a finalidade não de fornecer uma rota mais rápida, mas para limitar o acesso de ônibus e transportes com finalidade comercial e controlar a velocidade dos automóveis que trafegariam por elas, permitindo a apreciação do ambiente em seu percurso (essas estradas podem ser classificadas como caminhos livres ou estradas do pedágio). A engenharia dessas estradas vinha acompanhada por jardins, que embelezavam o seu percurso, dando inicio ao reconhecimento de que era possível dirigir por prazer ${ }^{6}$.

Em 1929, nos Estados Unidos, foram iniciadas as obras de construção de mais um projeto de Estrada-Parque, com o nome de Memorial Vernon que ligaria os Estados da Virginia e de Washington. A estrada foi terminada em 1932, e baseou-se na Estrada-Parque de Westchester, mas com algumas características novas. O projeto desta estrada incorporou diversas tecnologias novas no desenho, nas pontes, na sua pavimentação, e na construção, com o objetivo de proteger as características cênicas e restringir o aumento do processo de ocupação dessas áreas. Foi incorporada uma passagem de pedestres, uma ciclovia, o que aumentou o uso recreacional e

\footnotetext{
${ }^{6}$ Informações disponível em: http://www.fhwa.dot.gov/infrastructure/scenichistory.cfm. Acesso em: 20/11/2005.
} 
apreciação da paisagem natural. Estas idéias passaram a ser utilizadas como modelos para a construção de outras estradas-parque, que vêm evoluindo devido a impactos ambientais advindos do desenvolvimento econômico, assim as mesmas passaram a ser criadas com o propósito de preservação.

Essa UC, embora não tenha sido contemplada no SNUC, vem sendo criada em alguns Estados brasileiros, como Mato Grosso do Sul (EstradaParque Transpantaneira), Bahia (Estrada-Parque Baiana), Paraná (Estrada-Parque Serras Gaúchas e Graciosa), São Paulo (Estrada-Parque de Itu), Goiás (Estrada-Parque Chapada dos Veadeiros) entre outros. Como não há uma legislação específica em âmbito federal para esta unidade, vem sendo considerada por esses governos estaduais como Área Especial de Interesse Turístico (AEIT), Área de Proteção Ambiental (APA) ou Área de Relevante Interesse Ecológico (ARIE), (DOUROJEANNI 2003).

Em uma Estrada-Parque, segundo Dourojeanni (2003:17), "a faixa de rodagem pode ter as mais diversas características, desde uma via simples de chão até uma rodovia expressa de via dupla. Em geral, o tráfego de caminhões é proibido ou limitado, embora existam exceções a essa regra". $\mathrm{O}$ autor também salienta que estas estradas devem ter um portal de entrada e um posto de controle e pedágio, além de serem vistas de forma distinta de uma estrada comum, por terem características diferentes como sinalização e informação sobre as paisagens naturais visíveis em seu percurso e sobre a fauna local. Possuem também mirantes para a observação da paisagem, passagem de animais (para evitar acidentes com espécies que transitam em certos trechos), ciclovias, pontes estreitas, sonorizadores, quebra-molas, radares para controlar o trânsito. Essa unidade deve ser monitorada pela polícia florestal ou ambiental e deve ter uma faixa lateral de proteção dos dois lados para preservar a paisagem visível a partir da estrada.

Para o manejo desta unidade, segundo Dourojeanni (2003:19), devem ser tomadas medidas especiais, como a manutenção da sinalização e dos equipamentos de redução de controle de velocidade, o manejo da vegetação de beira de estrada (que reduz a visibilidade da paisagem), a presença constante de patrulhas policiais (evitando excessos de velocidade), controle especial de cargas perigosas (combustíveis, agrotóxicos, que possam ter impacto desastroso na biota). As Estradas-Parque são criadas com o intuito de valorizar as belezas existentes em determinadas regiões e a sua criação exige o envolvimento da comunidade que a circunda, devendo fazer parte de um conselho de gestão da unidade.

Apesar desta unidade, conforme descrita pelos autores citados, apresentar-se como uma importante unidade de conservação, faltam diretrizes para serem instituídas, o que tem acarretado na formação de Estradas-Parque pelo Brasil, de modo equivocado, vindo de encontro às definições citadas, gerando assim problemas ambientais, sociais e econômicos no local de implantação.

\section{DILEMAS E DIÁLOGOS}

De acordo com Bernardes (2005), o Brasil abriga de 10 a $20 \%$ do número de espécies conhecidas no planeta e possui a responsabilidade de criar e executar mecanismos e estratégias que possam abarcar a manutenção desta riqueza biológica. Necessitando de uma política ambiental atuante e especifica que venha contemplar a conservação do meio ambiente; respeitando as diferenças geopolíticas entre as regiões brasileiras; refletindo-se nos níveis diferentes e muito variáveis de desenvolvimento socioeconômico, uso e ocupação dos solos e qualidade de vida em geral.

A constituição brasileira em seu art.225 garante o direito do cidadão ao ambiente sadio: "Todos tem direito ao meio ambiente ecologicamente equilibrado, bem de uso comum do povo e essencial à sadia qualidade da vida, impondo-se ao Poder Público e a coletividade o dever de defendê-lo e preservá-lo para as presentes e futuras gerações".

Observa-se que não cabe apenas ao Poder Público o dever de preservação do meio ambiente, mas a toda coletividade em que os meios

Sociedade \& Natureza, Uberlândia, 20 (1): 161-176, jun. 2008 
representativos da sociedade como associações, cooperativas, ONGs, dentre outras, possuem um papel de fundamental importância, fiscalizando as aplicações das leis de interesse direto ou indireto na vida dos cidadãos, assegurando bem estar às gerações atuais e futuras, havendo, assim, uma luta pela defesa dos direitos ambientais que venha a garantir o caráter público. Concomitantemente, Estados e municípios têm se utilizado de mecanismos próprios de gestão ambiental, para o planejamento e execução de estratégias regionais ou locais. Estas ações atuam de forma integrada às atividades exercidas pelo poder público federal. As agências governamentais atuam, formais ou informalmente, na gestão do meio ambiente ou geram demandas de ação dos órgãos atuantes na área ambiental. Aliado a esse conjunto de instituições, está a comunidade ambientalista: às organizações não governamentais, as comunidades científicas e representantes do setor empresarial. A participação de todos esses setores, fornecendo subsídios às tomadas de decisão está implícita no conceito de desenvolvimento sustentável.

O estabelecimento do SNUC, segundo Bernardes (2005), foi apenas um dos itens na agenda da comunidade ambientalista e de diversos outros atores empenhados na tarefa de cumprir os compromissos assumidos pelo país quando assinou e ratificou a Convenção da Diversidade Biológica em 1992.

A política ambiental prevê a criação de UCs, e através dela muitos governos estaduais a utilizam como estratégia de desenvolvimento local, formando UCs sem nenhuma efetividade de manejo e podem trazer poucos benefícios para a conservação e preservação dos ecossistemas, exemplo disso, podem ser as Estradas-Parque instituídas por políticas locais.

A definição de Estrada-Parque feita por Da Ré e Arcari (apud Silva 1996), citada anteriormente, quando comparada às Estradas-Parques do modo existente no Brasil, provoca indagações sobre este termo. A "Estrada-Parque Chapada dos Veadeiros", em processo de implantação desde 2004, não atende às especificações feitas pelo autor. Por exemplo, a definição "alto valor educativo", supõe que os transeuntes deveriam respeitar as normas estabelecidas na estrada, não existe neste caso, pois, segundo relatos da comunidade residente em seu entorno, constantemente observa-se atropelamentos de animais, apesar da existência de placas de sinalização ao longo da estrada: "canso de ir a Alto Paraíso e ver animais mortos na estrada..." (sic) $)^{7}$, "trafego de bicicleta diariamente, por esse trecho e encontro muitos animais mortos pela estrada" (sic) ${ }^{8}$. Como pode então ser considerada como de alto valor educativo?. Figura 4.

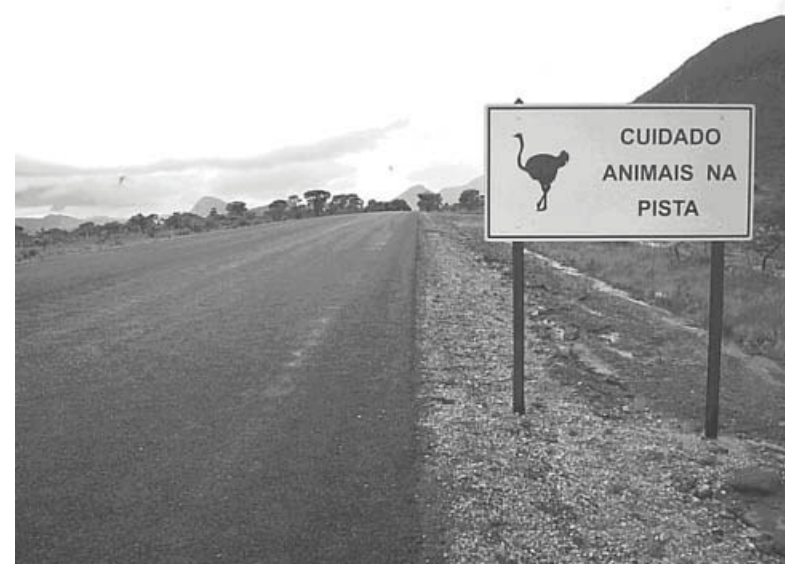

Figura 4. Vista Estrada-Parque - Placas de Sinalização. Fonte: Autoria própria.

7 Informação verbal: entrevista realizada com Marcio , morador local, em 14/11/05.

${ }^{8}$ Informação verbal: entrevista realizada com Francisco, morador local, em 15/11/05. 
A denominação "alto valor cultural", também nem sempre é verdadeira, pois nesta estrada se observa nenhum trabalho de resgate da cultura local, "Os desenhos de animais nas placas, foram feitos por uma pessoa que talvez nunca tenha visto o animal que foi desenhado, pois a Ema parece uma galinha e o Veado parece um cabrito"(sic) $)^{9}$, "Não sei como surgiu o nome Morro da Baleia, pois aqui nós sempre a chamamos de - Ferro de Passar, Morro da Baleia foi um nome dado por alguém que não consultou os moradores locais" (sic $)^{10}$. Estes relatos demonstram que não houve o envolvimento "ativo" da comunidade, quando da construção da estrada, acarretando na perda das características culturais da região.

Da - Ré e Arcari (apud Silva 1996) argumentam que "certas normas devem ser estabelecidas na Estrada-Parque sobre a velocidade de trânsito, ausência de letreiros publicitários ou cartazes, faixa de proteção, pavimentação, sinalização, curvas, ciclovias, de forma a permitir a ampla observação do panorama”.
A Agência Ambiental do Estado de Goiás ${ }^{11}$ regulamentou, em sua licença ambiental, que a velocidade máxima permitida na "Estrada-Parque Chapada dos Veadeiros" é de $60 \mathrm{~km} / \mathrm{h}$, porém, observou-se que esse limite não é respeitado e que não há fiscalização. Figura 5 .

Ao percorrer trechos já pavimentados dessa estrada, verifica-se a existência de uma ciclovia que não oferece segurança aos ciclistas, pois é uma faixa estreita, também utilizada como acostamento de carros, "No projeto divulgado, havia um corredor verde entre a rodovia e a pista de ciclismo. Não foi feito a estrada que foi colocada no telão, não há sinalização adequada e o ciclista não obedece à faixa dos carros e vice-versa" (sic) ${ }^{12}$. Outra característica observada é a erosão nas proximidades da própria margem da rodovia, o que demonstra que não foi feito um trabalho de recuperação no entorno desta. O EIA/ RIMA, segundo o gerente do Parque Nacional da Chapada dos Veadeiros, não consta o que deve e o que não deve ser feito no entorno da estrada, no que diz respeito a sua conservação, manutenção e cuidados com a biodiversidade existente.

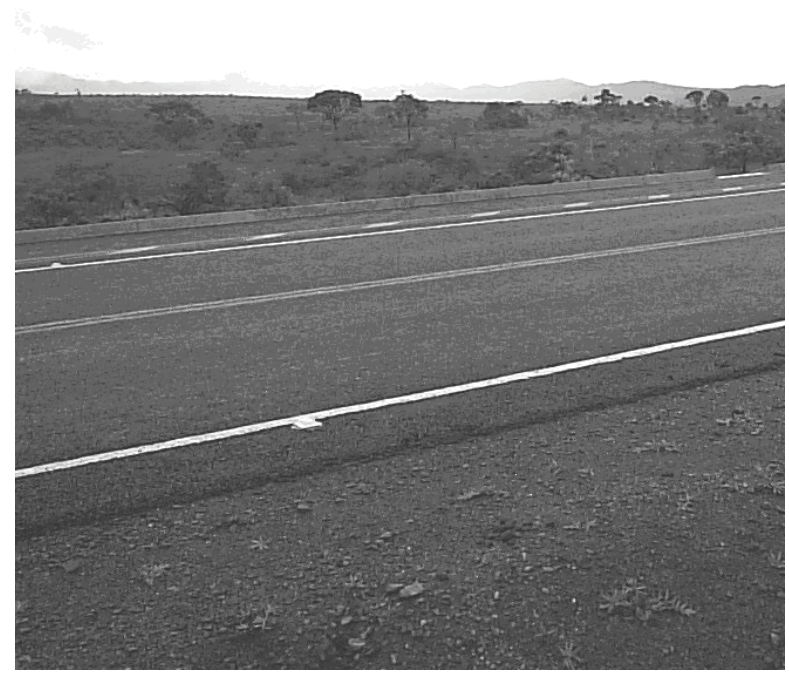

Figura 5. Vista Estrada-Parque - Ciclovia. Fonte: Autoria própria.

\footnotetext{
9 Informação verbal: entrevista realizada com Francisco, morador local, em 15/11/05.

${ }^{10}$ Idem: nota anterior.

${ }^{11}$ Fonte: Jornal o Popular 09/05/2004. Disponível em: http://www2.opopular.com.br/. Acesso em: 17/11/2005.

${ }^{12}$ Informação verbal: entrevista realizada com Antônio, morador local, em 15/11/05.
} 
Uma das características que difere as estradas parque de outras estradas é o fato de existir passagens de animais; túneis e redes, entretanto, isso não foi constatado na "Estrada-Parque Chapada dos Veadeiros", pois, segundo relatos essas duas técnicas que visariam à proteção a fauna, estavam contemplados no projeto original, quando apresentado à comunidade em Alto Paraíso em forma de audiência pública, mas não foram executadas, "Foi divulgada de uma maneira, mas estou vendo de outra... o que eu soube é que seria construída uma estrada com passagens de animais, com mirantes, bem organizadas com segurança para ciclistas, mas eu não estou vendo nada disso..." (sic) $)^{13}$, "faltou verbas para a construção das passagens de animais" (sic) $)^{14}$.

A comunidade local aponta que a estrada trouxe pontos positivos e negativos para a região. Após a pavimentação da estrada o fluxo de turismo aumentou, pessoas não visitavam São Jorge devido às precárias condições da estrada, atualmente é possível conhecer o local com facilidade e em carros de passeio. Ao longo do perímetro da estrada já surgiram oito diferentes tipos de pousadas.

Um ponto negativo, ressaltado pela comunidade, é que com a pavimentação da estrada, é possível que ocorram mudanças no perfil do turista, que antes permanecia mais tempo no povoado de São Jorge. Agora, visto que há maior acessibilidade aos atrativos, poderá ser desencadeado um turismo de massa e de curta duração, reduzindo o faturamento do comércio local.

A implantação de uma Estrada-Parque, nas condições apresentadas, mostra-se como um projeto ambiental não coerente com a conservação do meio ambiente, tendo sido implantada como forma de compensação para as comunidades locais. Os equívocos existentes na Chapada dos Veadeiros devem ser analisados para que não venha a acontecer em outras localidades. Neste contexto, a análise realizada, serve de base para a discussão de uma suposta proposta de implantação de uma EstradaParque na região do Jalapão.

Essas duas regiões possuem características em comum, como por exemplo as mais altas altitudes de seus Estados; áreas de grande interesse ecológico; grande desnível topográfico entre chapadas, morros testemunhos e extensas veredas; formação vegetal com fisionomia semelhante (exceto seus elementos endêmicos); baixa infra-estrutura urbana em seu entorno; especulação e "corrida imobiliária" em ascensão; região de baixo índice de desenvolvimento econômico por uma pedologia inadequada à pecuária ou agricultura moderna (Jalapão com seu solo arenoso, Veadeiros com solo laterizado por cristais); relativo isolamento de comunidades rurais em vias de integração ao mercado econômico do ecoturismo; forte pressão por seu desenvolvimento através do ecoturismo tido como a única alternativa de geração de renda; (exceto as "chapadas" do Jalapão, desconsideradas localmente como parte integrante dessa região); uso de técnicas agropecuárias tradicionais como a aplicação de queimadas como a fonte de renovação de pastagens; uso de seixos para a manutenção do eixo da estrada de terra (tido pelos entrevistados como um procedimento técnico inadequado à conservação dos leitos de rios e córregos). Além desses fatores, essas duas regiões, possuem uma unidade de conservação na categoria parque segmentada por eixos rodoviários.

Conforme citado anteriormente, o SEUC - TO considera Estrada-Parque como uma unidade de conservação de uso sustentável, de acordo com o art. 27 em sua Subseção V, “A Estrada-Parque é instituída compreendendo o leito de parte ou totalidade da estrada e as faixas de domínio de notável valor panorâmico, cultural ou recreativo". No parágrafo $1^{\circ}$, a administração da Estrada-Parque é realizada em conjunto com os órgãos de transporte e meio ambiente, e no parágrafo $2^{\circ}$, o poder público incentiva o turismo sustentável e a educação ambiental, ao longo das Estradas-Parque.

\footnotetext{
${ }^{13}$ Informação verbal: entrevista realizada com João, morador local, em 14/11/05.

${ }^{14}$ Informação verbal: entrevista realizada com Marlene, vereadora de Alto Paraíso, em 14/11/05.
} 
A proposta de Estrada-Parque no Jalapão, entre São Felix do Tocantins e Mateiros, de acordo com SEPLAN (2001), evidencia a necessidade de melhoria do acesso terrestre, como forma de benefício às populações locais, aumentando o fluxo de turistas, procurando desenvolver medidas para evitar o acesso desordenado aos atrativos e, conseqüentemente, impactos ambientais para a região.

A estrada entre São Felix e Mateiros é caracterizada por belezas cênicas e atrativos turísticos com locais propícios à instalação de mirantes. Esse roteiro, segundo DUTRA (2004), tem sido explorado por um turismo inadequado, pois ainda não houve um planejamento turístico, o que tem ocasionado a degradação dos atrativos. Figura 6.

Um dos principais problemas observados

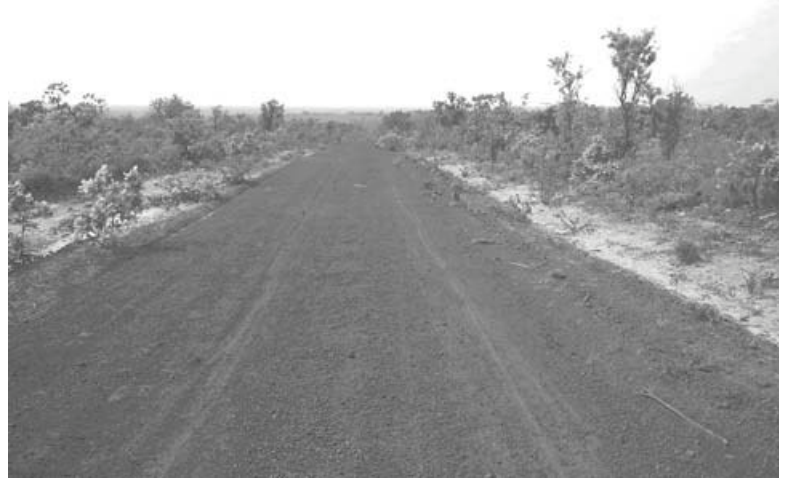

Figura 6. Estrada entre os municípios. Fonte: Autoria própria.

A transformação desta estrada em uma UC poderá gerar também conflitos com as cinco comunidades locais (Prata, Sussuapara, Galheiros, Fazenda Nova e do Carrapato), pois elas não foram informadas sobre o que seria uma estrada parque e vêem na convencional pavimentação da estrada uma perspectiva de melhoria de vida. Segundo relatos da comunidade, "... o asfalto melhoraria o transporte..." (sic) ${ }^{15}$. neste trecho são as queimadas feitas pelas comunidades locais, no período da seca, com a finalidade, segundo o Instituto Natureza do Tocantins (NATURATINS) que atua na região, de desenvolver atividades agrícolas e pecuária de subsistência. Nesta perspectiva, as paisagens cênicas contrastam com as áreas antropizadas sendo necessário ações conservacionistas por parte dos órgãos públicos e da sociedade organizada. Figura 7.

A transformação da estrada São Felix a Mateiros, com extensão de $60 \mathrm{~km}$, em Estrada-Parque (única via de acesso para as comunidades da região), poderia resguardar as paisagens cênicas ao seu entorno, pois se considerada UC, surgirá restrições de uso do solo em sua proximidade, o que colaboraria para a diminuição das queimadas e ajudaria na conservação do ambiente.

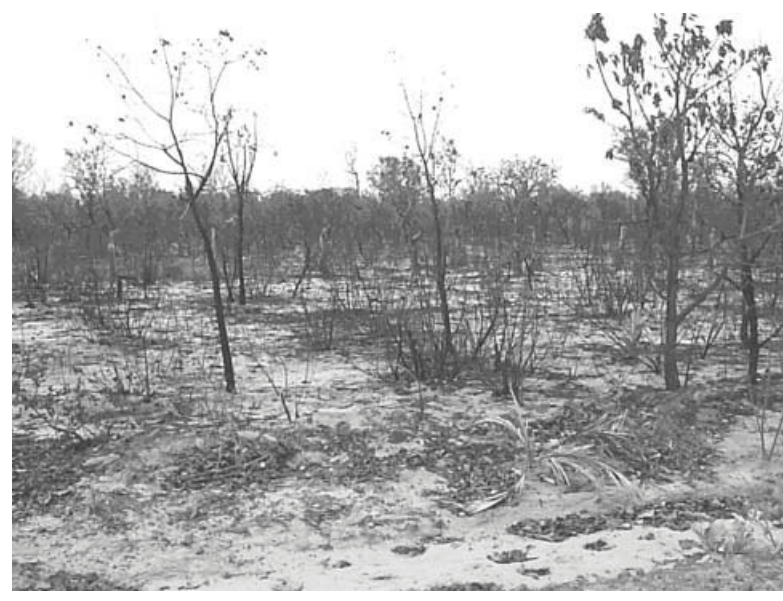

Figura 7. Vegetação queimada no entorno da estrada de São Felix do Tocantins a Mateiros.

Fonte: Autoria própria.

Tais expectativas podem não ser atingidas, no caso de uma UC, devido a restrições que podem surgir, o que levaria ao descontentamento da comunidade local.

A implantação de uma Estrada-Parque nesta região possivelmente repercutirá em problemas sociais, assim como vem acontecendo na "EstradaParque Chapada dos Veadeiros", cuja comunidade da

${ }^{15}$ Informação verbal: entrevista realizada com Ana, moradora local, em 30/10/05. 
região vem demonstrando insatisfação por não atender aos diferentes interesses. Por outro lado, a EstradaParque, se administrada de acordo com os padrões citados por Dourojeanni (2003), Da - Ré e Arcari (apud Silva 1996), poderá gerar renda para o seu manejo e conservação.

As estradas-parque enquanto UCs precisam ser questionadas, porque se o objetivo principal desta é o desenvolvimento sustentável e a preservação ambiental, as políticas ambientais devem procurar atender o interesse coletivo, baseado na justiça e na igualdade entre a natureza e o homem; estabelecendo um contrato natural, que segundo Moura (1996), possibilita uma nova percepção sobre o recurso natural, que deixa de ser visto apenas como valor econômico. Este contrato muda o meio político, que passa a se preocupar com o todo, ou seja, as decisões políticas são tomadas de acordo com o mundo natural.

Percebe-se que no caso da "Estrada-Parque Chapada dos Veadeiros", houve tentativa de consolidar esse contrato, visto que a estrada passava por um trecho de uma unidade de conservação parque nacional, devendo ser considerados tanto os impactos que a estrada poderia vir a causar, naquele ambiente, quanto os impactos causados à comunidade local. Porém, o contrato não tem sido cumprido, sendo a questão ambiental apenas institucionalizada no conceito de Estrada-Parque, como forma compensatória para a comunidade local, por meio de uma política ambiental. Em verdade, legalmente dar esse título àquele percurso é meramente fantasioso, pois segundo a Lei $\mathrm{n}^{\circ} 14.247 / 2002$ que estabelece o SEUC do Estado de Goiás, não existe este tipo de categoria como unidade de conservação, ao contrário da Lei $\mathrm{n}^{\circ} \mathrm{N}^{\circ} 1.560 / 2005$ que instituiu o SEUC do Estado do Tocantins, onde na seção II, Art.18, Subseção V contempla as EPs.

Neste contexto, tem-se feito apenas um contrato sócio-político que leva em consideração apenas à relação social, ou seja, os interesses da sociedade os interesses da sociedade, vendo a natureza como uma propriedade, sendo necessário um contrato que legitime a posse da mesma (MOURA 1996).

\section{CONSIDERAÇÕES FINAIS}

Este estudo buscou analisar o conceito de Estrada - Parque em duas regiões de grande potencial ecoturístico e econômico, localizadas no Bioma Cerrado. Pretendeu-se, aqui, identificar os aspectos relevantes e prioritários para a denominação de uma Estrada-Parque como unidade de conservação.

Embora falte um ordenamento mais atuante para essas unidades, muitos governos estaduais e municipais as utilizam como um "rótulo", como conservação ambiental local, cujo significado e características não são claras, já que não há uma política ambiental federal que legitime normas específicas para esse tipo de unidade de conservação.

Estados e municípios brasileiros utilizam as políticas ambientais locais como ferramenta para a execução de políticas públicas que possam produzir efeitos que, em sua grande maioria, reflitam o interesse de seus gestores. Como exemplo, temos a "Estrada-Parque Chapada dos Veadeiros", cujo projeto inicial previa uma estrutura integrada com o meio ambiente, mas, na sua implantação tais medidas integradoras não foram contempladas, vindo a frustrar a comunidade local e fragilizar o ecossistema.

A realidade apresentada durante os estudos realizados demonstra que a "Estrada Parque na Chapada dos Veadeiros" necessita de melhorias tanto na infra-estrutura quanto na própria denominação e adequação do termo na região. Já no Jalapão é necessário haver mais estudos sobre a região a fim de incorporar e incentivar uma participação atuante da comunidade em todo o processo de implementação, levando em consideração as especificidades da região, contribuindo assim para que não haja mais equívocos com relação à política aplicada.

Conforme os depoimentos coletados nas duas regiões, percebe-se que existem semelhanças quanto aos anseios e pessimismos das comunidades com relação ao que a estrada proporciona e o que poderá proporcionar para o desenvolvimento local. 
Proposta de estradas-parque como unidade de conservação: dilemas e diálogos entre o Jalapão e a Chapada dos Veadeiros Veruska Dutra, Aracélio Colares, Lúcio Flavo Marini Adorno, Keile Magalhães, Kelson Gomes

Nesse sentido, a política ambiental seria um meio jurídico de garantir o espaço público e a defesa dos direitos ambientais para comunidade. No entanto os dispositivos legais são pouco específicos em relação à Estrada-Parque como UC. Embora esteja presente em alguns Sistemas Estaduais de Unidades de Conservação, a Política Ambiental Federal nega juridicamente este modelo de unidade de uso sustentável, mas permite a existência de políticas ambientais estaduais e municipais autônomas para criarem suas categorias de UCs.

Essa questão de inconstitucionalidade federal da implantação de Estrada-Parque ganha uma nova ótica a partir da aprovação do Plano Estratégico Nacional de Áreas Protegidas - PNAP que por também ser considerada um elemento integrador da paisagem, sob um regime de uso especial, vale-se como um território tutelado com o objetivo de auxiliar espacialmente na manutenção e o uso sustentável da biodiversidade diante da conectividade com as outras modalidades de espaços naturais protegidos. Como uma de suas metas é integrar as unidades de conservação a paisagens terrestres e outras áreas protegidas, mediante abordagem ecossistêmica até o ano de 2012, surge que se esclareça o papel das EPs nesse percurso, além de se estar atento a todos as discussões presentes e futuras sobre essa temática.

Ao analisarmos o conceito de Estrada-Parque, enquanto unidade de conservação, percebemos que são muitos os desafios para a sua convertibilidade em área efetivamente de anteparo conservacionista. Ainda que como unidade de conservação in situ as EPs sejam extremamente inviáveis para a proteção de espécies endêmicas, o que há ainda que ser avaliado é como ela tem a capacidade de diminuir a pressão antrópica sobre as UCs de proteção integral que permitem visitação pública. Estes fatores se evidenciam claramente na forte atratividade das duas regiões estudadas, através da alta procura feita por eco turistas e aventureiros; dado o aumento do turismo interno no Brasil na atualidade com a própria política federal de regionalização do turismo.

Quando o assunto trata de desenvolvimento e conservação são vários os atores envolvidos, principalmente no que diz respeito à melhoria de estradas. A construção de estradas gera discussões, visto que são tidas como sinônimo de desenvolvimento local para aquelas comunidades isoladas dos grandes centros econômicos, embora sejam, também formas degradantes do meio ambiente. Para as comunidades que residem nas proximidades de áreas protegidas, a discussão é ainda maior, pois a ligação dessas com outros centros ocasiona conflitos ambientais, sociais e políticos.

Como conciliar então a conservação e os anseios de comunidades que vivem nas proximidades de unidades de conservação, com difícil acesso? A Estrada-Parque mostra-se como uma possibilidade de ferramenta estratégica para despertar atitudes integradas e atividades complementares diante da busca do desenvolvimento sustentável para essas regiões. Para que isso ocorra, ela necessita de uma legitimação efetiva pela política ambiental, para que assim todos os atores envolvidos nesse desafio sejam priorizados no processo, deixando de ser apenas uma medida de compensação que vai ao encontro dos interesses de uma minoria.

A implantação de uma Estrada-Parque não significa que os problemas de uma determinada região estarão resolvidos. É necessário todo um processo de planejamento no sentido de continuidade do processo educativo, preservacionista e turístico. Para tanto, é preciso a existência constante de fiscalização e controle não só da Estrada-Parque, mas, principalmente, da política adotada e executada, o que implica no cumprimento de um contrato natural e na atuação política da sociedade.

\section{REFERÊNCIAS}

ARAUJO, R. M. P. de. Estrada-Parque Pantanal: uma ferramenta de conservação da biodiversidade pantaneira. Dissertação de Mestrado em Gestão e Política Ambiental, UnB-CDS: Brasília, 2001.

BERNARDES, A.T. Projeto Biodiversidade no Desenvolvimento Série "Estudos-de-Caso"1: Brasil

Sociedade \& Natureza, Uberlândia, 20 (1): 161-176, jun. 2008 
- Unidades de Conservação Federais Brasil. Disponível em: http://www.wcmc.org.uk/biodev/ case\%20study/brazil pg1.pdf. Acesso em: 24/11/ 2005.

BUENO, M., BEHR, M. Jalapão expedição científica e conservacionista. Brasília: IBAMA, 2002.

CONSTITUIÇÃO, 1988. Constituição da República Federativa do Brasil: Promulgada em 5 de outubro de 1988. Organização do texto: Juarez de Oliveira. 4 ed. São Paulo: Saraiva, 1990. 168p. (Série Legislação Brasileira).

DA-RÉ, M e ARCARI, R. A rodovia como ordenador espacial: uma proposta de Estrada Parque. III $^{\circ}$ Encontro Ibero-Americano do Setor Transportes, Curitiba, 1998.

DOUROJEANNI, M.J. Estradas Parque, uma oportunidade pouco explorada para o turismo no Brasil. Natureza \& Conservação, v.1, n ${ }^{\circ}$, p.16-20, abril, 2003.

DUTRA, V.C. Um novo olhar do turista sobre a natureza: foco Jalapão. 2004. 93f. Monografia (Graduação em Turismo) - Centro Universitário Luterano de Palmas, Palmas.

ESTADÃO. Apresenta informações a respeito da Chapada dos veadeiros. Disponível em: http:// www.estadao.com.br/ciencia/noticias/2003/ago/15/ 271.htm. Acesso em: 27/11/2005.

ESTUDO DE IMPACTO AMBIENTAL - EIA/RIMA. Rodovia GO-239, trechos entroncamento GO 118/ BR-010 com GO-132. Governo do Estado de Goiás, Secretaria dos Transportes e Obras Públicas Departamento de Estradas de Rodagem. CONFLORA, 1998.

FHWA - FEDERAL HIGHWAY ADMINISTRATION. Apresenta informações sobre o histórico de estradas parques nos Estados Unidos. Disponível em: http://www.fhwa.dot.gov/ infrastructure/scenichistory.cfm Acesso em: 23/11/ 2005.

INSTITUTO BRASILEIRO DO MEIO AMBIENTE E DOS RECURSOS NATURAIS RENOVÁVEIS IBAMA. Apresenta informações sobre o Parque Nacional da Chapada dos Veadeiros. Disponível em: http://www.ibama.gov.br/parna_veadeiros/. Acesso em: 20/10/2005.

JORNAL O POPULAR. Apresenta na reportagem de 09/05/2004, informações sobre a Chapada dos Veadeiros. Disponível em: http:// www2.opopular.com.br/. Acesso em: 17/11/2005

MACARTHUR, R. H.; WILSON, E. O. An equilibrium theory of insular zoogeography. Evolution, v. 10, n. 6, p. 373-87, 1963.

MOURA, M. O papel do estado na política ambiental. In: Sustentabilidade política \& a política ambiental federal no Brasil - 1989/1994. Brasília: UNB/ICPRI, 1996, cap.II, 53-58.

NETIUM. Apresenta informações sobre a região do Jalapão. Disponível em: www.bsb.netium.com.br/ ivan/jalapao/jalapao.jpg. Acesso em: 28/11/2005.

SNUC - SISTEMA NACIONAL DE UNIDADES DE CONSERVAÇAO. Lei federal nº9985/2000.

SECRETARIA DE PLANEJAMENTO E MEIO AMBIENTE - SEPLAN. Apresenta informações a respeito do Parque Estadual do Jalapão. Disponível em: www.seplan.to.gov.br/dma/areas protegidas/ area protegida informacoes uc.htm. Acesso em: 01/ $12 / 2005$.

SECRETARIA DE PLANEJAMENTO E MEIO AMBIENTE - SEPLAN. Diagnóstico turístico da região do Jalapão. Palmas, 2001.

SECRETARIA DE PLANEJAMENTO E MEIO AMBIENTE - SEPLAN. Subsídios e proposta de trabalho para o projeto jalapão. Palmas, 1996. 
Proposta de estradas-parque como unidade de conservação: dilemas e diálogos entre o Jalapão e a Chapada dos Veadeiros Veruska Dutra, Aracélio Colares, Lúcio Flavo Marini Adorno, Keile Magalhães, Kelson Gomes

VIA ECOLÓGICA. Apresenta informações a respeito da Chapada dos Veadeiros. Disponível em: http:// www.viaecologica.com.br/guiasecologicos/ veadeiros/imagens/mapas/veadeiros.htm. Acesso em: 26/11/2005. 